\title{
New Complex for Enhancing Drag Reduction Efficiency
}

\author{
Emsalem Faraj Hawege and Hayder A. Bari
}

\begin{abstract}
Polymers have long been recognized as an effective drag reduction agent for strategic pipeline system. Unfortunately, such efficiency ends when the polymer molecule degrades in the pipeline especially when it flows through the pump. The aim of this work is to enhance the polymer's efficiency through addition of a surfactant. In particular, the present work investigated the drag reduction performance as well as degradation characteristics of anionic polymer polyacrylic acid (PAA) in the presence of a non-ionic surfactant (Tween 20). Rotating disk apparatus (RDA) and closed-loop liquid circulation (pipeline) techniques were employed in the study, and various surfactant effects, PAA concentrations and rotating speeds were tested. The results showed that the PAA drag reduction efficiency increased in the presence of Tween 20 . Almost 37\% drag reduction (\%DR) was observed at $1200 \mathrm{rpm}$. Additionally, the influence of surfactant on enhancing the drag reduction performance of PAA was evident when the investigation was carried out in the closed-loop liquid circulation system.
\end{abstract}

Index Terms-Polyacrylic acid (PAA), tween 20, Drag reduction, $R D A$.

\section{INTRODUCTION}

Drag reduction is widely used in many industrial applications such as waste water treatment, transportation of oils, firefighting, heating and cooling rings, water transportation, biomedical and in the area of hydraulic and jet machinery [1]-[4].

Many research investigations have been carried out on the concept of skin friction of fluids and associated drag reduction techniques using polymeric additives. Dodge and Metzner [5], [6] as well as Lumley [7] highlighted the importance of wall shear stress where the polymer macromolecule stretched as a result of fluctuating strain rate. However, they also reported that these stretches did not occur in the viscous sub-layer close to the wall.

According to Lumley [7], the stretch of randomly coiled polymers in turbulent flow mode plays a huge contribution to drag reduction. Tiederman [8] and Virk [9] further reported from their experimental investigations that drag reduction (DR) is restricted at a certain asymptote value.

In another study on maximum DR asymptote, Warholic et al., [10] reported that the Reynolds shear stress tends to be insignificant near the maximum DR asymptote. Thus, the

Manuscript received November 16, 2014; revised March 15, 2015.

Emsalem Faraj Hawege is with the Faculty of Chemical and Natural Resources Engineering, University Malaysia Pahang, 26300 Kuantan, Pahang, Malaysia, University Malaysia Pahang, 26300 Kuantan, Pahang, Malaysia (e-mail: emsalemfrg@yahoo.com).

Hayder A. Bari is with the Centre of Excellence for Advanced Research in Fluid Flow (CARIFF), University Malaysia Pahang, 26300 Kuantan, Pahang, Malaysia, University Malaysia Pahang, 26300 Kuantan, Pahang, Malaysia. drag reduction by polymers is best explained through the viscoelastic impact of the polymer chains in the solution [11], [12].

Tesauro et al., [13] suggested there is a translation of energy from the velocity fluctuations to the polymer chain. The energy is maintained when the polymer chain is in its stretched position, and when it eases back from such extended state to its equilibrium state. The disadvantage of polymeric additives, however, is that they "degrade" mechanically and thermally when exposed to shear stresses in the turbulent liquid flow [14]. When this occurs, their drag reduction efficiency significantly declined.

Some studies [15]-[18] found that the addition of surfactant into a polymer solution could be an effective technique to decrease the mechanical degradation of polymer especially in high temperature flow systems. The precise mechanism of DR by surfactant solutions is still uncertain, although certain researchers have pointed out that their viscoelastic effects could also influence turbulent DR [19].

Polymer and surfactants interact in two ways. First, the interaction is possible via negative- or positive-charged polymers with oppositely charged ionic surfactant. The electrostatic interactions play a major role in such interaction. Critical aggregation concentration (CAC) has been reported to be of lower orders of magnitudes than the critical micelle concentration (CMC) in this case. The second interaction is that between non-ionic polymer and ionic surfactant or similar-charged polymer-surfactant complex. The CAC could be near the surfactant CMC. A hydrophobic interaction between the hydrophobic portions of both polymer and surfactant could be the driving force for this type of interaction [20]-[23].

The interaction between similar-charged ionic polymer and ionic surfactant complex (similar charge) has been studied by Kim et al., [23]. They found that the \% DR increased after a little amount of surfactant was added to the polymer solution. The increase in the \% DR which occured was suggested to have been caused by the hydrophopic interaction between the polymer and surfactant.

In this work, the interaction and rheological properties of polymer (PAA)-nonionic surfactant (Tween 20) complex was studied using RDA and closed-loop liquid circulation techniques. The influence of different concentrations of polymer and surfactant, and effects of different rotational speeds on DR efficiency were investigated in a rotating disk apparatus. The conformation variation of PAA-Tween 20 complex was determined using transmission electron microscopy (TEM). Finally, the effect of polymer degradation on pressure drop as a function of time was investigated in a closed-loop liquid circulation (to simulate a pipeline) system. 


\section{MATERIALS AND MethodS}

\section{A. Materials}

Polyacrylic acid and Tween 20 with molecular weight $1,250,000 \mathrm{~g} / \mathrm{mol}$ and $1228 \mathrm{~g} / \mathrm{mol}$, respectively. Both additives were purchased from Sigma Aldrich and used without further purification.

\section{B. Method}

\section{1) Rheology test}

The rheology test for this experimental work was carried out using Brookfield DV-III Ultra Programmable Rheometer. After samples preparation, the first step undertaken was to verify their viscosity and this was done using Brookfield viscometer of about $12.1 \mathrm{~cm}$ high and 8.25 circumference testing container. It has a temperature controlled water bath at a varying temperature of about $25^{\circ} \mathrm{C} \pm 0.05^{\circ} \mathrm{C}$.

The samples were investigated at various rotations per minutes (rpms) where the spindle was operated between 20 to $200 \mathrm{rpm}$. The coaxial cylinder rotational viscometer could operate at different shear stresses depending on the cylindrical spindle. The sample was poured at the annular space in between the spindle and the tube. The required rpm was altered from 20-200 rpms. The values of the shear rates and shear stresses were recorded accordingly. Same procedure was applied to all remaining concentrations.

In summary, the viscosity of each sample was determined before subsequent tests were carried out using the rotational disk apparatus (RDA). Any sample which concentration did not meet the required viscosity was discarded.

\section{2) Rotating disk apparatus}

The rotational disk apparatus is capable to perform rheology tests on samples of various physical properties (either solvent alone or mixed with the DRAs). In this case, the DRAs to be used have not been tested before. In addition, the RDA is also used to investigate the influence of torque on the samples at various rotational speeds.

The RDA equipment is made up of a $88 \mathrm{~mm}$ high and $165 \mathrm{~mm}$ wide stainless steel container with a removable lid of about $60 \mathrm{~mm}$ thickness. The rotating disk has about $148 \mathrm{~mm}$ circumference and $3 \mathrm{~mm}$ thickness. The cylinder has a storage capacity of about $1.2 \mathrm{~L}$ of liquid sample. The disk rotational speed is computer controlled at a maximum rotational speed up to $3000 \mathrm{rpm}$ and the torque value/s could be read on a computer display system. The computer display system is manufactured by Xin Jie Electronic Co. Ltd with other features such as servo motor model of DS2-20P7-AS servo driver and capacity of $0.75 \mathrm{~kW}$.

The major application of the RDA was to verify the mechanical resistance of the samples before they were tested in the pipeline (closed-loop liquid circulation). It was also used to identify the samples which produced the desired viscosity. In this case, the rheology was tested for same materials of different quantities, volumes and concentrations. Same method was used for sample preparations, in $1.2 \mathrm{~L}$ of water. The test was carried out using water as a control, followed by the various DRA additives. Pure deionized water and the DRA additives were investigated using the RDA to determine the torque at different rpms (usually 50-3000 rpms).

Graphical representation of the RDA is illustrated in Fig. 1 below:

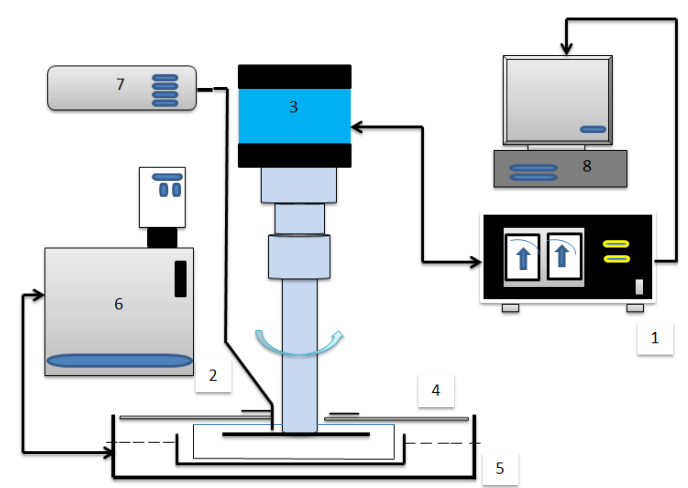

Fig. 1. Graphical image of a rotating disk apparatus for drag reduction measurement: 1) speed controller, 2) thermocouple, 3) motor, 4) solution container, 5) water bath, 6) water-circulating system, 7) thermometer, and 8) PC.

\section{3) Closed-loop liquid circulation system (pipeline)}

A closed-loop liquid circulation system was employed to observe the pressure drop versus time. Same method was used for sample preparations, in 1.2 L of water The samples and the reference were examined in the closed-loop liquid circulation system to observe and compare the pressure drop versus time for both water and samples.

\section{RESUlT AND DisCUSSION}

\section{A. Rotating Disk Apparatus}

Fig. 2. illustrates the effect of rotational speed on the torque of different concentrations of PAA in comparison with the torque of pure water (as reference). It could be seen that the torque decreased slightly with increasing PAA concentration compared to the torque of pure water. The torque of pure water at $2700 \mathrm{rpm}$ was 29 N.M, while the torque of PAA at 50 and 1000 ppm was 26 N.M at the same rpm. This indicates that increasing the PAA concentration does not affect its drag reduction efficiency.

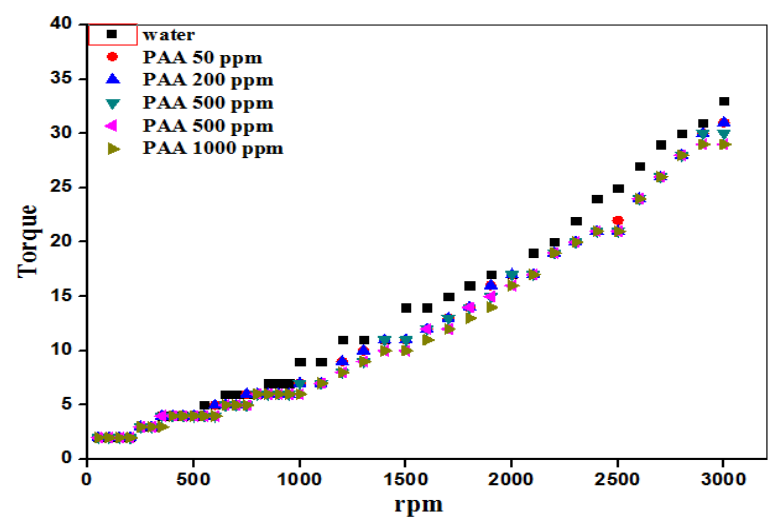

Fig. 2. Effect of rotational speed on the torque of different concentrations of PAA in water.

Fig. 3. shows the relationship between the torque and the rotational speed for different concentrations of Tween 20. It is obvious that the torque decreased a little when the 
concentration of Tween 20 was increased.

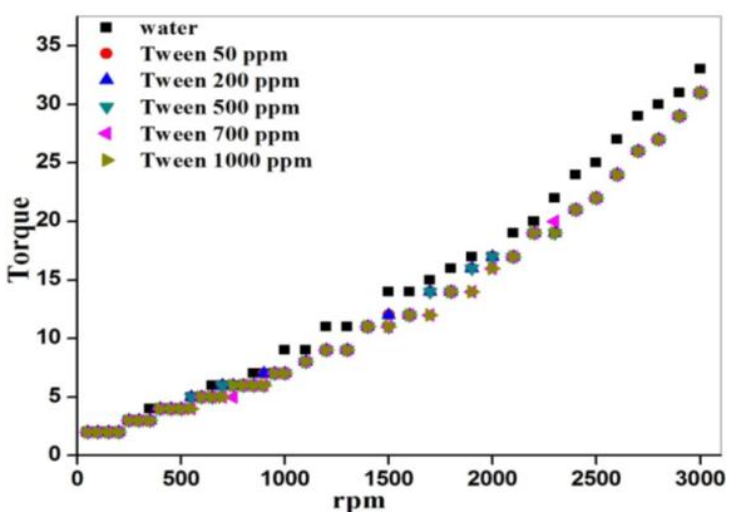

Fig. 3. The relationship between the torque and the rotational speed of different concentrations of Tween 20.

Despite the increase in either PAA or Tween 20 concentration, the torque showed very little change. However, increasing the concentration of the PAA-Tween 20 mixture showed a significant change in torque. Fig. 4 explains the function between rotational speed and torque of different concentrations of PAA-Tween 20 mixtures. At $2700 \mathrm{rpm}$, the torque of water (reference) was 29 N.M. At the same rpm, the torque of 50 and $1000 \mathrm{ppm}$ of PAA-Tween 20 mixtures was 26 and 22 respectively. It was suggested that such decrease in torque occurred following the hydrophobic interaction between PAA-Tween 20 complexes [24].

On the other hand, the drag reduction of the PAA-Tween 20 mixture increased when the surfactant concentration was increased to $1000 \mathrm{ppm}$. As observed, the interaction between PAA and Tween 20 was very strong at 1000 ppm [22], [24].

We can see this interaction through the TEM image shown in Fig. 5.

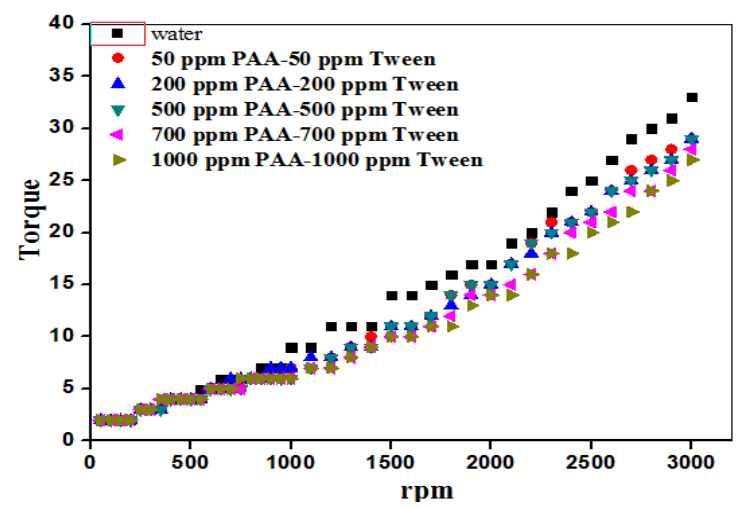

Fig. 4. The function between the rotational speed and the torque of PAA-Tween 20 mixtures, in different concentrations, in water.

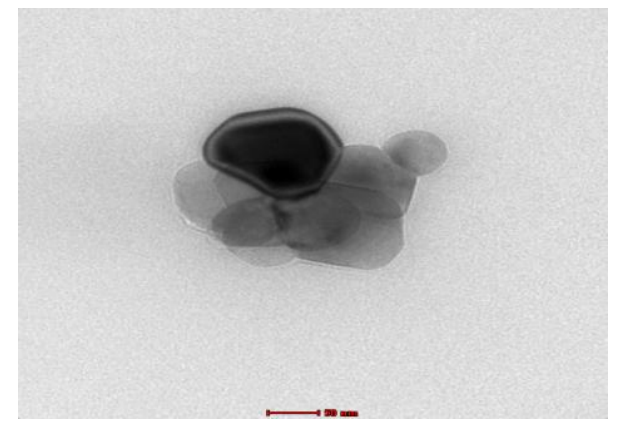

Fig. 5. TEM image of PAA -Tween mixture.

\section{B. Closed Loop Liquid Circulation (Pipeline)}

Fig. 6 illustrates the comparison between pressure drop $(\Delta$ $P$ ) values of reference (water) and different concentrations of PAA-Tween 20 mixtures as a function of time. It could be seen that the $\Delta \mathrm{P}$ decreased when the concentration of the mixtures increased. The $\Delta \mathrm{P}$ of reference was around 101 Pascal $(\mathrm{Pa})$, while $\Delta \mathrm{P}$ of $50 \mathrm{ppm}$ PAA- $50 \mathrm{ppm}$ Tween was almost $95 \mathrm{~Pa}$ during the first $10 \mathrm{sec}$. After that $\Delta \mathrm{P}$ decreased slightly to $93 \mathrm{~Pa}$. By increasing the mixture concentration to $1000 \mathrm{ppm}$, the $\Delta \mathrm{P}$ decreased to $90 \mathrm{~Pa}$ during first $10 \mathrm{sec}$. After $15 \mathrm{sec}, \Delta \mathrm{P}$ of the mixture decreased rapidly to $87 \mathrm{~Pa}$. This decrease in $\Delta \mathrm{P}$ of the mixture might have occurred following the hydrophobic interaction between PAA and Tween 20.

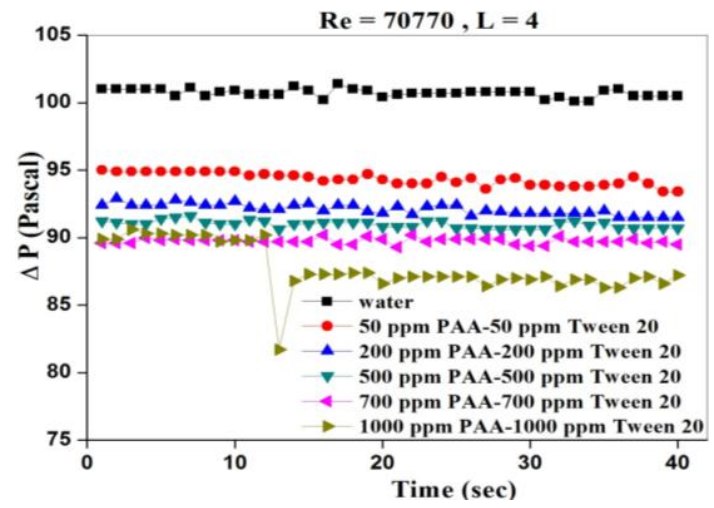

Fig. 6. Compare the values of the pressure drop of reference (tap water) and PAA - Tween 20 mixtures as a function of time.

\section{CONCLUSION}

In conclusion, we managed to study various effects of different concentrations of polymer and surfactant, along with different rotational speeds on DR efficiency using RDA. The DR efficiency attributed by the PAA-Tween 20 mixture was found to be significantly higher than that of pure PAA. In addition, it could be seen that $\Delta \mathrm{P}$ decreased dramatically when the concentration of PAA-Tween 20 complex was increased as a function of time.

\section{ACKNOWLEDGEMENT}

The authors are grateful to University Malaysia Pahang, for financial assistance.

\section{REFERENCES}

[1] D. F. Anghel, J. L. T. Herrera, F. M. Winnik, W. Rettig, and R. V. Klitzing, "Steady state fluorescence investigation of pyrene labeled poly(acrylic acid)s in aqueous solution and in the presence of sodium dodecyl sulfate," Langmuir, vol. 18, pp. 5600-5606, 2002.

[2] H. Diamant and D. Andelman "Onset of self-assembly in polymer-surfactant systems," EPL (Europhysics Letters), vol. 48, vol. $170,1999$.

[3] D. Dodge and A. Metzner, "Turbulent flow of non-Newtonian systems," AIChE Journal, vol. 5, no. 2, pp. 189-204, 1959.

[4] K. Gasljevic, G. Aguilar, and E. Matthys "On two distinct types of drag-reducing fluids, diameter scaling, and turbulent profiles," Journal of Non-Newtonian Fluid Mechanics, vol. 96, no. 3, pp. 405-425, 2001.

[5] E. D. Goddard and K. P. Ananthapadmanabhan, "Interactions of surfactants with polymers and proteins," CRC Press Boca Raton, FL, 1993.

[6] P. Hansson and B. Lindman, "Surfactant-polymer interactions," Current Opinion in Colloid and Interface Science, vol. 1, no. 5, pp. 604-613, 1996. 
[7] I. Harwigsson and M. Hellsten "Environmentally acceptable drag-reducing surfactants for district heating and cooling," Journal of the American Oil Chemists' Society, vol. 73, no. 7, pp. 921-928, 1996.

[8] H. A. AbdulBari, S. N. Kamarulizam, and R. C. Man, "Investigating drag reduction characteristic using okra mucilage as new drag reduction agent," Journal of Applied Sciences, vol. 11, no. 14, pp. 2554-2561, 2011.

[9] M. Hellsten, "Drag-reducing surfactants," Journal of Surfactants and Detergents, vol. 5, no. 1, pp. 65-70, 2002.

[10] J. T. Kim, C. A. Kim, K. Zhang, and C. H. Jang, "Hyoung Jin Choi Colloids and Surfaces," A Physicochem Eng. Aspects, vol. 391, pp. $125-129,2011$.

[11] K. Gasljevic, G. Aguilar, and E. F. Matthys, "Measurement of temperature profiles in turbulent pipe flow of polymer and surfactant drag-reducing solutions," Phys. Fluids, vol. 19, pp. 1-18, 2007.

[12] J. Lumley, "Drag reduction by additives," Annual Review of Fluid Mechanics, vol. 1, no. 1, pp. 367-384, 1969.

[13] J. Lumley, "Drag reduction in turbulent flow by polymer additives," Journal of Polymer Science: Macromolecular Reviews vol. 7, no. 1, pp. 263-290, 1973.

[14] A. Metzner and A. Metzner, "Stress levels in rapid extensional flows of polymeric fluids," Rheologica Acta, vol. 9, no. 2, pp. 174-181, 1970

[15] K. J. Mysels, "Napalm mixture of aluminum disoaps," Industrial \& Engineering Chemistry, vol. 41, no. 7, pp. 1435-1438, 1949.

[16] N. J. Kim, J. Y. Lee, S. M. Yoon, C. B. Kim, and B. K. Hur, "Drag reduction rates and degradation effects in synthetic polymer solution with surfactant additives," J. Ind. Eng. Chem, vol. 6, pp. 412-418, 2000.

[17] S. Suksamranchit, A. Sirivat, and A. M. Jamieson, "Polymer surfactant complex formation and its effect on turbulent wall shear stress," J. Colloid Interface Sci., vol. 294, pp. 212-221, 2006.

[18] S. Suksamranchit and A. Sirivat, "Influence of ionic strength on complex formation between poly(ethylene oxide) and cationic surfactant and turbulent wall shear stress in aqueous solution," Chem. Eng. J., vol. 128, pp. 11-20, 2007

[19] C. Tesauro, B. Boersma, M. Hulsen, P. Ptasinski, and F. T. M Nieuwstadt, "Events of high polymer activity in drag reducing flows," Flow, Turbulence and Combustion, vol. 79, no. 2, pp. 123-132, 2007.

[20] P. Virk, "Drag reduction fundamentals," AIChE Journal, vol. 21, no. 4, pp. 625-656, 1975 .

[21] M. Warholic, H. Massah, and T. Hanratty, "Influence of drag-reducing polymers on turbulence: Effects of Reynolds number, concentration and mixing," Experiments in Fluids, vol. 27, no. 5, pp. 461-472, 1999.

[22] W. Brostow, S. Majumdar, and R. P. Singh, "Drag reduction and solvation in polymer solutions," Macromol Rapid Commun, vol. 20, pp. 144-147, 1999.
[23] Y. Zhang, J. Schmidt, Y. Talmon, and J. L. Zakin, "Co-solvent effects on drag reduction, rheological properties and micelle microstructures of cationic surfactants," J. Colloid Interface Sci, vol. 286, pp. 696-790, 2005.

[24] J. L. Zakin, J. Myska, and Z. Chara, "New limiting drag reduction and velocity profile asymptotes for nonpolymeric additives systems," AIChE Journal, vol. 42, no. 12, pp. 3544-3546, 1996.

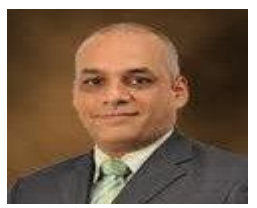

Hayder A. Bari comes from Iraq, he was born on September 3, 1973. He holds a bachelor of chemical engineering, Bagdad University, Bagdad, Iraq, 1996 master of chemical engineering, Bagdad University, Bagdad Iraq, $\mathrm{PhD}$ in chemical engineering, Bagdad University, Bagdad, Iraq

He now is the director of the Centre of Excellence for Advanced Research in Fluid Flow, CARIFF. Also, he is an associate professor in the faculty of chemical and natural resources engineering.

Dr. Hayder A. Abdulbari was granted his merit award for the best achievements in 2012 under "Invention Academics and Education order of Merit", Seoul, South Korea, December 15, 2012; gold medal in the British invention show 2013 for the invention natural graese, October 2013; gold medal for the best invention in industrial equipments in the invention \& new product exposition INPEX 2011, Pittsburgh, Pennsylvania, USA, 15-17 June 2011, for the invention entitled "Novel Mechanical Technique to Improve the Flow in Pipes."

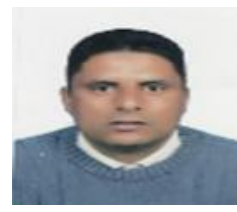

Emsalem Faraj Hawege comes from Libya, he was born on February 1, 1973. He holds a bachelor of chemical engineering, Faculty of Engineering, Al-Mergheb University, Al-Khoms Libya from 1992 to 1998, master of engineering in chemical and process engineering, Faculty of Engineering Al-Mergheb University, Al-Khoms Libya from 2004

to 2007 .

He is now a PhD student in the Faculty of Chemical and Natural Resources Engineering, Malaysia Pahang, he was also a lecturer at the Department of Chemical Engineering at Faculty of Engineering Al-Merghe University Al-Khoms, Libya from 2008 to 2010, he also was a lecturer at the Department of Chemical Technology-Msallata higher technical institute, Msallata - Libya from 2008 to 2010. Emsalem Faraj Hawege has won the silver award two times. He won the first silver medal in creation, innovation, technology \& research exposition, on March 5-6, 2014, at University Malaysia Pahang. He won the second silver medal in national, innovation and invention competition through exhibition (iCompEx'14), on March24-25, 2014, at Politeknik Sultan Abdul Halim Mu'adzam Shah, Jetra, Kedah. 